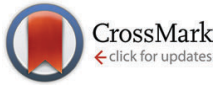

Cite this: Phys. Chem. Chem. Phys., 2016, 18, 1346

DOI: $10.1039 / c 5 c p 90226 f$

www.rsc.org/pccp

\section{Correction: Quantifying transient interactions between amide groups and the guanidinium cation}

\author{
V. Balos, M. Bonn and J. Hunger*
}

Correction for 'Quantifying transient interactions between amide groups and the guanidinium cation' by V. Balos et al., Phys. Chem. Chem. Phys., 2015, 17, 28539-28543.

We correct an error to our previous paper, ${ }^{1}$ which does not affect any of the conclusions in that paper, but changes some of the inferred values. For the extraction of the concentration of free NMA in solution from the measured dielectric spectra, as shown in Fig. 3, the contribution of the hydration, $S_{\text {hyd }}$ of $\mathrm{NaCl}$, $\mathrm{LiCl}$ and $\mathrm{MgCl}_{2}$, was calculated incorrectly. The erroneous calculation originates from the kinetic depolarization correction (eqn (S5) in the ESI of the original article):

$$
S_{\mathrm{KD}}^{\text {water }}=f \frac{S_{\text {Cavell }}^{\text {water }}}{\varepsilon_{\mathrm{s}}} \cdot \frac{\tau_{\text {water }}}{\varepsilon_{0}} \cdot \kappa,
$$

where, in the original analysis, we neglected the friction coefficient, $f$ (i.e. we assumed stick boundary conditions, $f=1$ ) for the calculation of $S_{\text {hyd }}$. Using more realistic ${ }^{2}$ slip boundary conditions $(f=2 / 3)$, the calculated values of $c_{\mathrm{NMA} \text {,free }}$ for $\mathrm{NaCl}, \mathrm{LiCl}$, and $\mathrm{MgCl}_{2}$ are accordingly lower. The corrected Fig. 3 is given below:

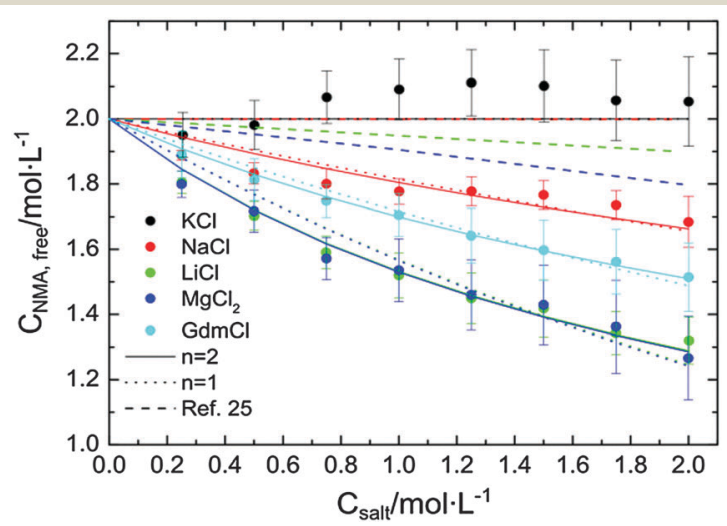

Fig. 3 Concentration of free NMA molecules as a function of salt concentration. The solid lines correspond to fits using eqn (3) with $n=2$, while the dotted lines show the corresponding fits assuming $n=1$. The dashed line shows literature results obtained using vibrational spectroscopy (ref. 25 of our paper). Error bars correspond to the standard deviation within at least 6 independent measurements.

The number of NMA molecules interacting with the different cations obtained from fitting eqn (3) to the data shown in Fig. 3 are $n_{\mathrm{LiCl}}=(2.8 \pm 0.4)$ and $n_{\mathrm{MgCl}_{2}}=(2.6 \pm 0.7)$. The featureless, nearly linear decrease in $c_{\mathrm{NMA} \text {,free }}$ upon addition of $\mathrm{NaCl}$ does not allow for determination of $n_{\mathrm{NaCl}}$ independent of $K\left(n_{\mathrm{NaCl}}=(16 \pm 15)\right)$.

The association constants assuming $n=2$ are reduced accordingly to $K=0.13 \mathrm{~L}^{2} \mathrm{~mol}^{-2}\left(\mathrm{Mg}^{2+}\right), 0.13 \mathrm{~L}^{2} \mathrm{~mol}^{-2}\left(\mathrm{Li}^{+}\right)$, and $0.04 \mathrm{~L}^{2} \mathrm{~mol}^{-2}\left(\mathrm{Na}^{+}\right)$. 
As the erroneous calculation only affected $S_{\text {hyd }}$ and for solutions of GdmCl $S_{\text {hyd }}=0$, our results for GdmCl are not altered. Thus, our main conclusions and the reported association constants between GdmCl and amide are not affected, except that the interaction of $\mathrm{GdmCl}$ with amides is not similar to $\mathrm{NaCl}$, but intermediate between $\mathrm{NaCl}$ and $\mathrm{LiCl}$.

\section{References}

1 V. Balos, M. Bonn and J. Hunger, Phys. Chem. Chem. Phys., 2015, 17, 28539-28543.

2 R. Buchner, G. T. Hefter and P. M. May, J. Phys. Chem. A, 1999, 103, 1-9.

The Royal Society of Chemistry apologises for these errors and any consequent inconvenience to authors and readers. 